\title{
Analisa dan Evaluasi : Akar Penyebab dan Biaya Sisa Material Konstruksi Proyek Pembangunan Kantor Kelurahan di Kota Solo, Sekolah, dan Pasar Menggunakan Root Cause Analysis (RCA) dan Fault Tree Analysis (FTA)
}

\author{
Kristanto Wibowo ${ }^{1}$, Sugiyarto ${ }^{2}$, Setiono ${ }^{3}$ \\ Jurusan Teknik Sipil, Fakultas Teknik, Universitas Sebelas Maret, Surakarta \\ Jalan Ir. Sutami Nomor 36A Kentingan Surakarta 57126, Indonesia \\ e-mail :kristantowibowo@,rocketmail.com
}

\begin{abstract}
ABSTRAK
Sisa material merupakan hasil sisa yang pasti muncul dalam sebuah proyek konstruksi berupa bahan atau material yang sudah tidak dapat difungsikan sebagaimana fungsinya dalam perencanaan dan berpeluang besar merugikan kontraktor apabila tidak dimanajemen dengan benar. Kerugian kontraktor yang dimaksudkan, salah satunya adalah membengkaknya biaya pelaksanaan proyek konstruksi. Root Cause Analysis (RCA) merupakan suatu metode analisis yang dipakai untuk menentukan penyebab utama suatu permasalahan dengan mengidentifikasi masalah paling umum atau paling terlihat kepada persoalan khusus yang merupakan akar dari masalah tersebut. Fault Tree Analysis (FTA) merupakan suatu metode analisis yang dipakai untuk menentukan seberapa berpengaruh penyebab-penyebab persoalan yang ada menyebabkan suatu kejadian penting 'top event' dalam satuan persen, menggunakan bantuan diagram ilustrasi berbentuk seperti cabang-cabang pohon, dan dihitung dengan rumus-rumus tertentu. Hasil analisa didapat jenis material yang paling banyak menjadi sisa material adalah besi dan genting keramik dengan persentase biaya sisa material berkisar dari $12,40 \%-14,50 \%$. Solusi untuk mengurangi sisa material antara lain : memberikan arahan kepada tenaga kerja agar lebih berhati-hati, dan menggunakan pekerja pembesian yang lebih efisien serta berpengalaman.
\end{abstract}

Kata kunci : biaya, sisa material, root cause analysis, dan fault tree analysis.

\begin{abstract}
Material waste is a certain thing in every construction project as a fault beginning purpose thing and it has a big chance to cause the cost damage if the contractor does not manage it well. Root Cause Analysis (RCA) is one of many analysis methods that is used to identify root cause from a problem. Fault Tree Analysis (FTA) is one of many analysis methods that is used to determine how much influence each intermediate events cause the top event in percent, use tree diagram, and be calculated with fault tree analysis's formula. The result : iron and ceramic are the biggest waste in cost percent about 12,40\%-14,50\%. The solution to decrease the cost waste material: best instruction to the workers, and choose the most efficient worker for truss job.
\end{abstract}

key words : cost, material waste, root cause analysis, and fault tree analysis.

\section{PENDAHULUAN}

Sisa material merupakan hasil tambahan yang pasti muncul dalam pengerjaan suatu proyek pembangunan. Sisa material dapat menimbulkan kerugian ataupun gangguan terhadap proyek, baik dalam pengerjaan di lapangan, maupun pembengkakan biaya / biaya berlebih yang sebenarnya tidak perlu dikeluarkan. Oleh sebab itu, penting bagi pihak kontraktor untuk menguasai manajemen sisa material konstruksi.

\section{TINJAUAN PUSTAKA}

Material konstruksi merupakan bahan bangunan yang dipakai dalam pelaksanaan proyek konstruksi. Proyek pembangunan perkantoran biasa menggunakan jenis material sebagai berikut :

Besi adalah salah satu jenis material yang paling banyak digunakan dalam bangunan. Sifatnya yang kuat dan memiliki ketahanan yang besar terhadap gaya tarik membuat orang beralih dari 
penggunaan kayu kepada besi. Besi berbeda dengan kayu yang sangat terbatas jumlahnya dan butuh waktu cukup lama untuk diproduksi kembali, besi sangat melimpah di alam. Besi memiliki ketahanan terhadap panas, namun mudah mengalami karat.

Kayu merupakan bagian dari batang tumbuhan yang mengeras karena mengalami pengayuan. Pada proyek pembangunan, kayu biasa digunakan untuk pekerjaan struktural seperti kolom dan balok. Sifat mekanis yang dimiliki kayu berhubungan dengan penggunaanya, antara lain untuk tiang diperlukan data keteguhan tekan sejajar serat, sedangkan untuk kuda-kuda diperlukan data keteguhan lentur statis, keteguhan tekan sejajar serat dan keteguhan geser. Kayu harus disimpan di tempat yang kering, tidak terkena sinar matahari secara langsung dan terhindar dari rayap dan serangga lain yang dapat merusak kayu.

Seng atau dalam bahasa Belanda zink, atau timah sari adalah unsur paling melimpah ke-24 di kerak bumi. Seng yang sering digunakan dalam bangunan berbentuk pelat, dapat menghantarkan panas, sedikit lentur namun kuat.

Galvallum adalah suatu bahan yang sudah mengalami proses galvanisasi, yaitu pemberian lapisan pelindung berupa seng terhadap besi atau baja agar tidak mengalami karat. Proses galvanisasi ini menggunakan metode celupan panas maupun elektrokimia. Galvallum sangat menguntungkan apabila digunakan sebagai penutup atap karena sangat ringan, yaitu sepersepuluh berat genteng keramik. Penutup atap galvallum cocok digunakan di daerah yang rawan gempa. Galvallum memiliki kelemahan mudah robek, dan mudah penyok bila diinjak. Polikarbonat adalah suatu kelompok termoplastik yang mudah dibentuk dengan dipanasi. Polikarbonat memiliki banyak keunggulan dibanding jenis plastic lain, antara lain : tahan panas, tahan benturan, dan sangat bening sehingga dapat meneruskan cahaya dengan baik. Polikarbonat memiliki kelemahan mudah pecah apabila terkena benturan keras, maupun terjatuh.

Genteng keramik merupakan salah satu jenis atap rumah yang sering digunakan di Indonesia karena relatif murah dan mudah diganti apabila ada yang pecah ataupun bocor, selain itu genteng keramik tahan terhadap panas dan hujan. Bahan baku pembuatan genteng keramik adalah tanah liat yang mengalami proses pembakaran, sehingga menjadi padat dan keras.

Menurut Gavilan dan Bemold (1994), sumber-sumber sisa material konstruksi dibagi menjadi enam kategori, antara lain:

a. Desain

b. Pengadaan Material

c. Penanganan Material

d. Residual

e. Pelaksanaan

f. Lain-lain

Kategori tersebut diteliti oleh Bossink dan Browers dan mendapatkan kesimpulan, yaitu sumber dan faktor penyebab kategori tersebut. Kategori tersebut diuraikan ke dalam tabel berikut :

Tabel 1. Sumber dan penyebab sisa material konstruksi menurut Gavilan dan Bernold

\begin{tabular}{ll}
\hline Sumber & Penyebab \\
\hline Desain & - Kesalahan pada dokumen kontrak \\
\hline & - Ketidaklengkapan dokumen kontrak \\
\hline & - Perubahan desain \\
\hline & - Memilih spesifikasi produk \\
\hline & - Memilih produk yang berkualitas rendah \\
\hline & - Kurang memperhatikan ukuran dari produk yang digunakan \\
\hline & - Desainer tidak mengenal dengan baik jenis-jenis produk yang lain \\
\hline & - Pendetailan gambar yang rumit \\
\hline & - Informasi gambar yang kurang
\end{tabular}




\begin{tabular}{|c|c|}
\hline & $\begin{array}{l}\text { - Kurang berkoordinasi dengan kontraktor dan kurang berpengetahuan } \\
\text { tentang konstruksi }\end{array}$ \\
\hline \multirow[t]{5}{*}{$\begin{array}{l}\text { Pengadaan } \\
\text { material }\end{array}$} & - Kesalahan pemesanan, kelebihan, kekurangan, dsb \\
\hline & - Pesanan tidak dapat dilakukan dalam jumlah kecil \\
\hline & - Pembelian material yang tidak sesuai dengan spesifikasi \\
\hline & - Pemasok mengirim barang yang tidak sesuai spesifikasi \\
\hline & $\begin{array}{l}\text { - Pengepakan kurang baik menyebabkan terjadi kerusakan dalam } \\
\text { perjalanan }\end{array}$ \\
\hline \multirow[t]{10}{*}{$\begin{array}{l}\text { Penanganan } \\
\text { material }\end{array}$} & - Kesalahan yang diakibatkan oleh tenaga kerja \\
\hline & - Peralatan yang tidak berfungsi dengan baik \\
\hline & - Cuaca yang buruk \\
\hline & - Kecelakaan pekerja di lapangan \\
\hline & - Penggunaan material yang salah sehingga perlu diganti \\
\hline & - Metode untuk menempatkan pondasi \\
\hline & $\begin{array}{l}\text { - Jumlah material yang dibutuhkan tidak diketahui karena perencanaan } \\
\text { yang tidak sempurna }\end{array}$ \\
\hline & $\begin{array}{l}\text { - Informasi tipe dan ukuran material yang akan digunakan terlambat } \\
\text { disampaikan kepada kontraktor }\end{array}$ \\
\hline & $\begin{array}{l}\text { - Kecerobohan dalam mencampur, mengolah dan menggunakan } \\
\text { material kerja yang tidak akurat, dll }\end{array}$ \\
\hline & $\begin{array}{l}\text { - Pengukuran dimensi yang tidak akurat sehingga terjadi kelebihan } \\
\text { volume }\end{array}$ \\
\hline \multirow[t]{5}{*}{ Residual } & - Sisa pemotongan material tidak dapat dipakai lagi \\
\hline & - Kesalahan pada saat memotong material \\
\hline & - Kesalahan pemasangan barang karena tidak menguasai spesifikasi \\
\hline & - Pengepakan \\
\hline & - Sisa material karena proses pemakaian \\
\hline Lain-lain & - Kehilangan akibat pencurian \\
\hline & $\begin{array}{l}\text { - Buruknya pengontrolan material di proyek dan perencanaan } \\
\text { manajemen terhadap sisa material }\end{array}$ \\
\hline
\end{tabular}

Root Cause Analysis (RCA) merupakan suatu metode untuk penyelesaian permasalahan, mencoba mengidentifikasi faktor penyebab dari suatu permasalahan atau kejadian yang tidak diharapkan. Root Cause Analysis merupakan suatu metode untuk membantu menjawab pertanyaan 'apa yang terjadi?', 'bagaimana bias terjadi?', dan 'mengapa itu terjadi?'. Tujuan utama metode ini adalah untuk mengidentifikasi faktor yang dinyatakan dalam bentuk alami, besaran, lokasi dan waktu akibat dari kebiasaan, tindakan dan kondisi tertentu yang harus diubah untuk menghindari kesalahan yang tidak perlu.

Metode Root Cause sering digunakan dalam menjalankan berbagai macam kegiatan bisnis, termasuk proyek pembangunan gedung dan semacam itu. Pengidentifikasian faktor utama penyebab sisa material menggunakan Metode Root Cause dapat memperoleh hasil yang tepat dan sistematis.

Fault Tree Analysis (FTA) adalah salah satu metode yang dapat digunakan untuk menentukan penyebab dari suatu kejadian. FTA terdiri dari top event fault merupakan kejadian yang ingin dianalisis, misal timbul sisa material genting; intermediate event fault merupakan kejadiankejadian yang mempengaruhi terjadinya top event fault dan masih bisa dijabarkan lagi ke dalam beberapa kejadian, misal pengadaan material; basic event fault merupakan kejadian paling dasar, sehingga tidak perlu dijabarkan lagi, misal pemesanan material tidak dapat dilakukan dalam 
jumlah kecil. Setiap kejadian dalam FTA dapat dihubungkan dengan 2 (dua) fungsi, yaitu AND, atau OR. AND $(\otimes)$ merupakan penggabungan, yang berarti kejadian atas dengan kejadian di bawahnya saling mempengaruhi (top event-intermediate event atau intermediate event-basic event). Sedangkan OR $(\oplus)$ merupakan persimpangan, yang berarti kejadian di bawah mengakibatkan kejadian di atasnya, namun tidak saling tergantung / terpengaruh.

Metode FTA memiliki beberapa langkah pengerjaan, sebagai berikut:

Langkah 1 : menentukan top event

Langkah 2 : mendaftar fault events apa saja yang terjadi selama proses pengerjaan

Langkah 3 : membuat fault tree diagram

Langkah 4 : memastikan urutan-urutan / posisi kejadian dalam diagram

Langkah 5 : kualitatif dan kuantitatif analisis

Langkah 6 : penaksiral kegagalan

Sisa material (waste) adalah kelebihan kuantitas material yang digunakan yang tidak menambah nilai (value) suatu pekerjaan. Berikut ini merupakan rumus yang digunakan untuk menghitung sisa material :

Sisa material $=$ Pembelian material - Stok material - Kebutuhan material

Biaya sisa material $=$ Sisa material $\times$ Harga satuan material

Persentase biaya sisa material $=\frac{\text { Biaya Sisa Material }}{\text { Total Biaya Material }} \times 100 \%$

Persentase total $=\frac{\text { Total Biaya Sisa Material }}{\text { Total Biaya Proyek }} \times 100 \%$

\section{METODE PENELITIAN}

Penelitian lapangan sisa material konstruksi dilakukan di kota Surakarta dan sekitarnya, Jawa Tengah, yaitu pada Proyek Pembangunan Kantor Kelurahan Jagalan, SMPN 11 Surakarta dan Pasar Grogol.

Studi literatur yang digunakan meliputi materi mengenai manajemen sampah konstruksi, baik itu cara mengidentifikasi sisa material, maupun cara menghitung satuan sisa material dengan memahami RAB, asbuilt drawing, laporan logistik, dan lain-lain. Pengumpulan data dilakukan dengan wawancara langsung di lapangan dengan pihak-pihak terkait, dan pengamatan data dari konstraktor seperti laporan keluar masuk dan pemakaian material, RAB proyek, asbuilt drawing.

Perhitungan data dilakukan dengan Microsoft Excel dengan langkah sebagai berikut :

Perhitungan Kebutuhan Material

Langkah pertama yang dilakukan adalah mengidentifikasi setiap item pekerjaan dan jenis material yang digunakan, kemudian menghitung kuantitas kebutuhan material berdasarkan gambar konstruksi (asbuilt drawing). Selanjutnya, seluruh hasil perhitungan Bill of Quantity dimasukkan ke dalam tabel kebutuhan material yang disusun berdasarkan jenis pekerjaan dan jenis material. Setiap angka dijumlahkan menurut kolom jenis material masing-masing.

Perhitungan Pembelian Material

Pembelian material dihitung berdasarkan laporan harian proyek sehingga dapat diketahui jumlah material yang didatangkan setiap hari selama masa pelaksanaan proyek, termasuk stok material terakhir yang disimpan. Setiap angka pembelian dijumlahkan menurut kolom jenis material masing-masing.

Perhitungan Sisa Material (Waste)

Sisa material (waste) adalah kelebihan kuantitas material yang digunakan yang tidak menambah nilai (value) suatu pekerjaan. 


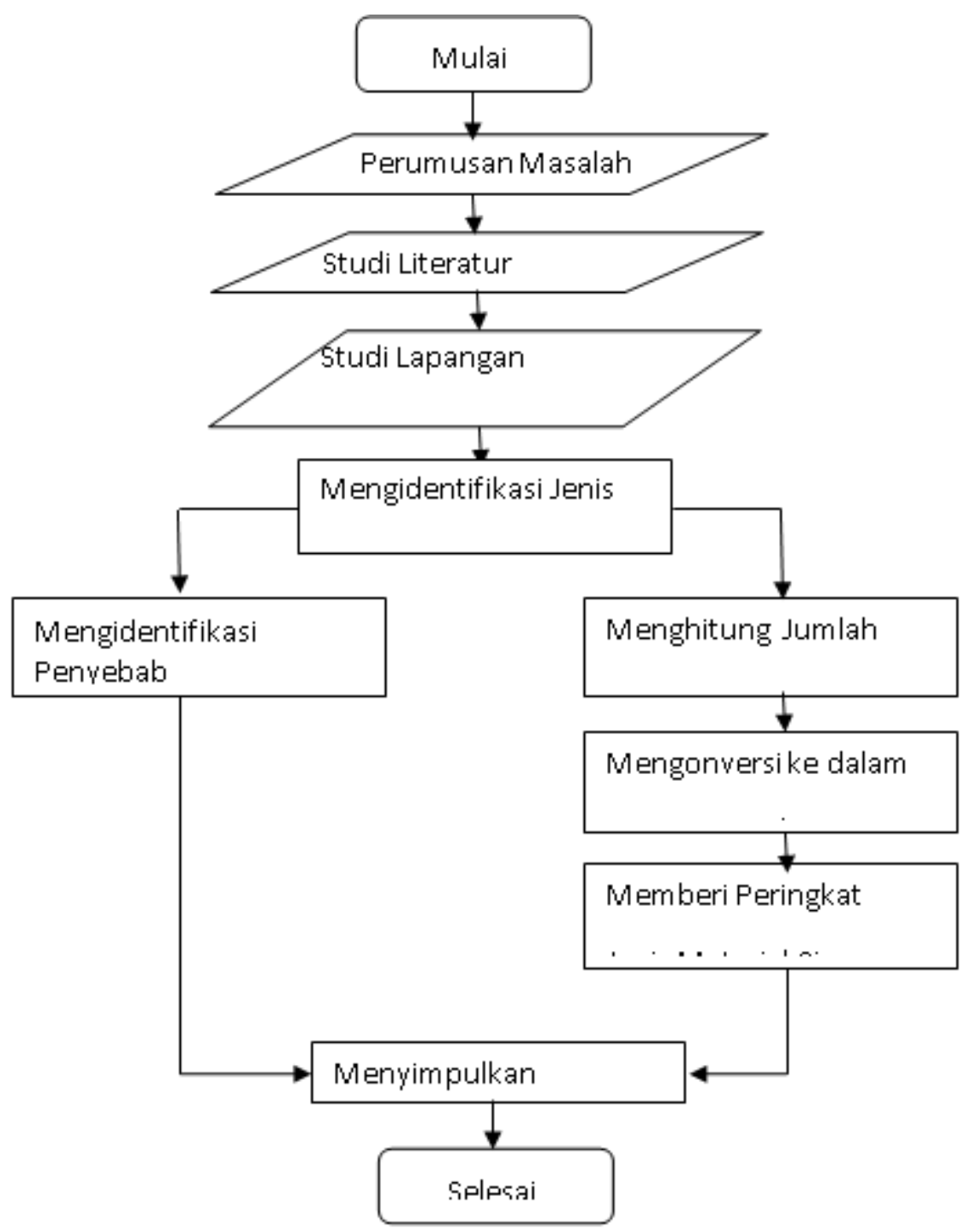

Gambar 1. Diagram alir penelitian

\section{HASIL DAN PEMBAHASAN}

Dari perhitungan menggunakan Microsoft Excel didapati presentase biaya sisa material sebagai berikut :

Tabel 2. Persentase Biaya Sisa Material

\begin{tabular}{lllll}
\hline \multirow{2}{*}{ No Jenis Material } & \multirow{2}{*}{ Biaya Sisa } & Biaya Beli & Presentase Biaya \\
\cline { 4 - 5 } & & Material & Sisa Material \\
\hline Kantor Kelurahan Jagalan & & & \\
\hline 1 & Besi & 18783704 & 141711875 & $13.20 \%$ \\
\hline 2 & Kayu & 21755726 & 226403550 & $9.61 \%$ \\
\hline 3 & Cat & 791197.26 & 17112000 & $4.62 \%$ \\
\hline 4 & Seng & 84162.75 & 1328250 & $6.34 \%$ \\
\hline 5 & Galvallum & 4335099.7 & 63530000 & $6.82 \%$ \\
\hline 6 & Harplek & 3194185.2 & 39600000 & $8.07 \%$ \\
\hline
\end{tabular}




\begin{tabular}{lllll}
\hline 7 & Polikarbonat & 3822014 & 30682575 & $12.46 \%$ \\
\hline Presentase Total Sisa Material & 52766089 & 520368250 & $10.14 \%$ \\
\hline SMPN 11 Silir & & & \\
\hline 8 & Besi & 63231520 & 508200000 & $12.44 \%$ \\
\hline 9 & Cat & 2707376 & 57960000 & $4.67 \%$ \\
\hline 10 & Kayu & 21348024 & 205809030 & $10.37 \%$ \\
\hline 11 & Keramik genteng & 12685880 & 100878000 & $12.58 \%$ \\
\hline Presentase Total Sisa Material & 99972800 & 872847030 & $11.45 \%$ \\
\hline Pasar Grogol & & & \\
\hline 12 & Besi & 47022322 & 357850625 & $13.14 \%$ \\
\hline 13 & Cat & 1725920 & 42320000 & $4.08 \%$ \\
\hline 14 & Galvallum & 8500125 & 142500000 & $5.96 \%$ \\
\hline 15 & Polikarbonat & 2066757 & 18409545 & $11.23 \%$ \\
\hline 16 & Keramik/genteng & 841662 & 5796000 & $14.52 \%$ \\
\hline 17 & Kayu & 2880000 & 22680000 & $12.70 \%$ \\
\hline Presentase Total Sisa Material & 63036786 & 589556170 & $10.69 \%$ \\
\hline
\end{tabular}

Dari tabel 2. persentase biaya sisa material tersebut diketahui jenis material sisa yang persentase biayanya paling besar pertama adalah genteng keramik dan kedua adalah besi dengan persentase berkisar $12,40 \%-14,50 \%$, dengan faktor penyebab untuk genteng keramik, antara lain pengadaan, penanganan, dan pelaksanaan, seperti yang digambarkan dengan diagram fault tree di halaman berikut

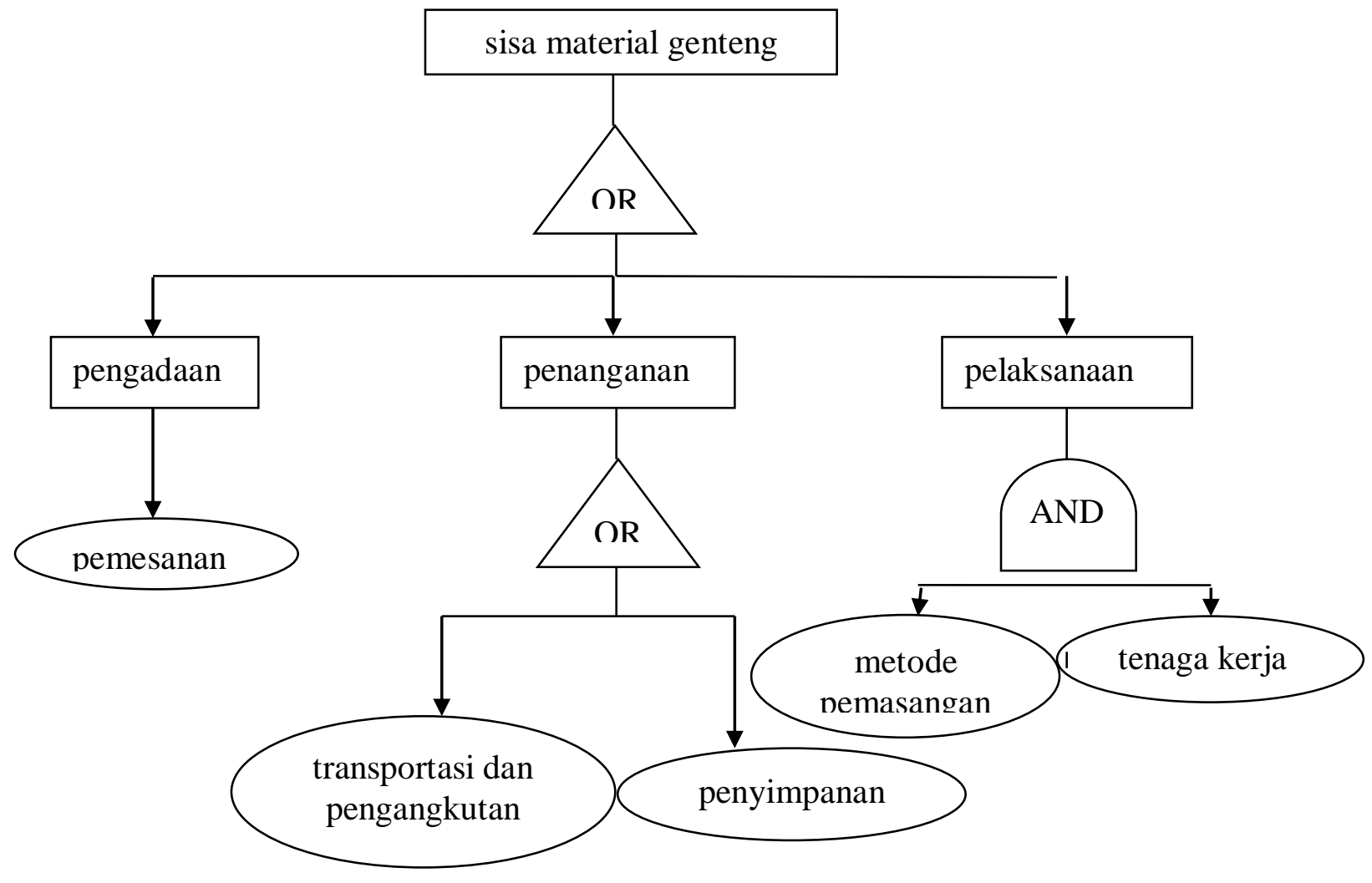

Gambar 2. Fault Tree Diagram 
Arti dari fault tree diagram tersebut adalah : munculnya sisa material genteng sebagai top event diakibatkan oleh 3 (tiga) intermediate events yang satu sama lain memberikan pengaruh terhadap top event secara tersendiri dan tidak saling mempengaruhi. Pada intermediate event pengadaan diakibatkan oleh basic event pemesanan yang tidak dapat dilakukan dalam jumlah kecil. Pada penanganan diakibatkan oleh transportasi dan pengangkutan material tidak dikemas dengan baik dan ditangani dengan kurang hati-hati, juga penyimpanan material yang kurang layak (sebagian tidak berada di dalam gudang). Pada pelaksanaan diakibatkan oleh metode pemasangan dan tenaga kerja yang saling mempengaruhi. Tenaga kerja yang ceroboh sangat memungkinkan jatuhnya genteng lalu pecah, apalagi ditambah dengan metode pemasangan yang kurang tepat seperti melempar genteng maupun meletakkan tumpukan genteng pada bagian atas dinding yang apabila terkena kaki tenaga kerja, dapat jatuh dan pecah.

Root Cause Analysis dilakukan dengan bantuan fishbone diagram, lalu dilanjutkan dengan why-why analysis di halaman berikut:

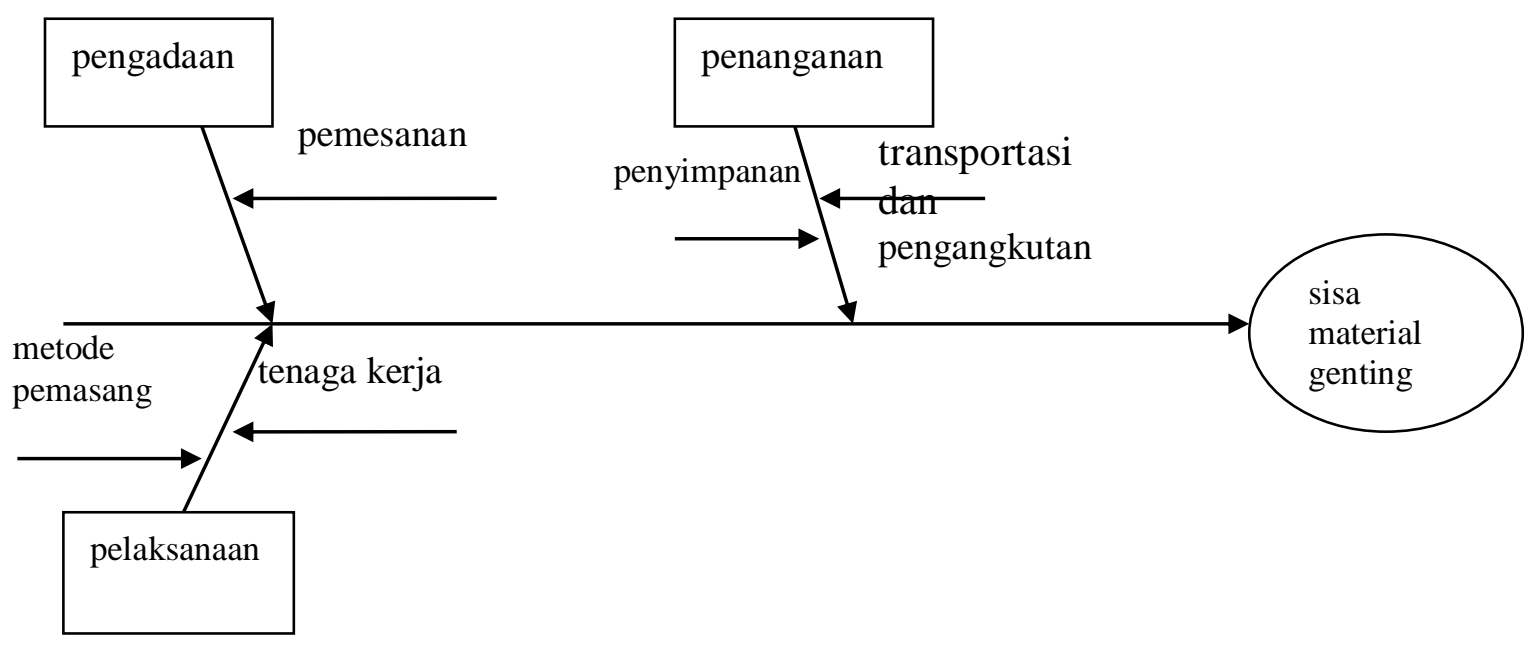

Gambar 3. Fishbone Diagram

Fisbbone diagram tersebut diperhatikan dengan seksama untuk menentukan akar penyebab utama dari munculnya sisa material genteng dan didapati pada transportasi dan pengangkutan.

Why-why analysis sebagai berikut :

Mengapa transportasi dan pengangkutan menjadi akar penyebab utama munculnya sisa material genteng?

Karena genteng-genteng hanya diikat menjadi tumpukan-tumpukan, sedang alas, antara tumpukan genteng di bawah dengan tumpukan di atasnya, serta bagian paling atas tumpukan / penutup tidak ada. (seharusnya menggunakan kardus sebagai alas untuk mengurangi benturan antar genteng selama perjalanan)

Mengapa antara tumpukan genteng tidak diberi alas / bantalan?

Karena ketergesaan pengiriman dengan mendatangkan dua truk sekaligus.

Mengapa terjadi ketergesaan dari pihak pengirim?

Karena pihak kontraktor yang menggesa-gesa pihak pengirim.

Mengapa pihak kontraktor menggesa-gesa?

Karena pihak kontraktor mengejar ketertinggalan yang terjadi di awal pekerjaan.

Mengapa pihak kontraktor mengalami ketertinggalan di awal pekerjaaan?

Karena penyedia jasa yang pertama tidak mau berkoordinasi dengan baik, sehingga penyedia jasa yang kedua kesulitan menyesuaikan dengan desain atau perencanaan awal.

Solusi : kontraktor sebisa mungkin tidak perlu mengambil proyek lanjutan yang statusnya kurang jelas (mangkrak) ataupun kontraktor bekerja keras sejak awal, melakukan brain storming 
untuk merevisi desain awal sehingga mendapatkan desain baru yang lebih mudah dipahami dan tidak perlu merombak bangunan awal.

\section{KESIMPULAN DAN SARAN}

Dari hasil penelitian, analisis data, dan pembahasan maka dapat ditarik beberapa kesimpulan sebagai berikut :

Jenis material sisa terbanyak pada proyek pembangunan Kantor Kelurahan Jagalan adalah besi dengan biaya sisa Rp. 18.783.704,00 yang berarti senilai 13,20\%.

Jenis material sisa terbanyak pada proyek pembangunan SMP Negeri 11 Surakarta adalah genting keramik dengan biaya sisa Rp. 12.685.880,00 yang berarti senilai 12,58 \%.

Jenis material sisa terbanyak pada proyek pembangunan Pasar Grogol adalah genting keramik dengan biaya sisa Rp. 841.662,00 yang berarti senilai 14,52\%.

Untuk menindaklanjuti penelitian ini, diperlukan beberapa koreksi yang harus diperhatikan agar dapat dijadikan sebagai pedoman dan acuan bagi penelitian-penelitian selanjutnya agar dapat lebih baik. Adapun saran-saran untuk penelitian selanjutnya antara lain sebagai berikut : Bagi jasa kontraktor, alangkah baiknya tidak mengambil proyek mangkrak untuk dilanjutkan, ataupun apabila terpaksa bekerja keras sejak awal, melakukan brain storming untuk merevisi desain awal sehingga mendapatkan desain baru yang lebih mudah dipahami dan tidak perlu merombak bangunan awal. Kontraktor sebaiknya mengenali wilayah proyek terlebih dahulu, mencangkup cuaca, kebiasaan penduduk sekitar, dan tempat mendapatkan pekerja lokal agar tidak perlu timbul terlalu banyak sisa material..

Bagi mahasiswa skripsi lain dak memilih proyek dengan peralihan jasa kontraktor agar tidak kesulitan mendapatkan data.

\section{DAFTAR PUSTAKA}

Bossink, B. A. G., and Brouwers, H. J. H., Construction waste: Quantification and source evaluation, Journal of Construction Engineering and Management,March 1996. pp. 55-60.

Gavilan, R. M., and Bernold, L. E., Source Evaluation of Solid Waste in BuildingConstruction, Journal of Construction Engineering and Management, September 1994. pp. $536-552$. 